\title{
NOTES
}

\section{HOW IMPORTANT IS DISAGGREGATION IN STRUCTURAL MODELS OF INTEREST RATE DETERMINATION?}

\author{
Benjamin M. Friedman*
}

A rapidly developing literature is currently investigating the determination of interest rates through the conceptual approach of the structural model. ${ }^{1}$ In brief, a structural model of asset prices (yields) is simply the combination of a representation of investors' demand for securities and a representation of borrowers' (or equity issuers') supply of securities, together with a market clearing condition. Such a model stands in contrast to the traditional approach of modeling interest rate determination using an unrestricted reducedform equation with the particular interest rate in question as the dependent variable. Since the structural model's implied expression for the interest rate is (except for any nonlinearities) a reduced-form equation that is restricted by the underlying asset demand and supply equations, the distinction between the structural and the traditional approaches is essentially equivalent to the difference between restricted and unrestricted estimation. ${ }^{2}$

A frequently expressed reservation about the structural modeling approach is that, while it is sound in principle, it is useful only in the context of a detailed sectoral disaggregation which creates added work in model-building and near impossibilities in forecasting applications. One of the key advantages of the structural approach is indeed the facility it provides for incorporating information pertinent to heterogeneous groups whose behavior may differ because of any of a number of economic or institutional factors. Hence, to date, economists who have developed this approach

Received for publication October 23, 1978. Revision accepted for publication March 13, 1979.

* Harvard University.

The author is grateful to Orlin Grabbe for research assistance and helpful discussions; to an anonymous referee for helpful comments on a previous draft; and to the National Bureau of Economic Research, the Alfred P. Sloan Foundation, and the National Science Foundation (grant APR7714160) for research support.

1 Recent examples include work by Bosworth and Duesenberry (1973), Dick (1978), Friedman (1977; 1979), Hendershott (1977), Roley (1977), and Silber (1970).

${ }^{2}$ See Friedman and Roley (forthcoming) for a discussion of the advantages of the structural modeling strategy as applied to interest rate determination. That paper also presents results for direct estimation of the specific reduced-form equation implied by the structural models specified in Friedman (1977; 1979). have typically done so within the context of at least some sectoral disaggregation, estimating several component demand and supply relationships for any one asset. This popularly presumed connection with sectoral disaggregation has led many economists to avoid the structural modeling approach, as small-model enthusiasts have shunned estimating so many sectoral equations, forecasters have despaired of formulating priors for future values of so many "exogenous" sectoral variables, and some economists have even rejected a priori the notion that sectoral detail matters for macroeconomic outcomes. ${ }^{3}$

The presumption of any necessary connection between structural interest rate modeling and sectoral disaggregation, however, is simply false. The structural versus reduced-form choice, and the aggregated versus disaggregated choice, are separate issues. While a structural model may incorporate sectoral detail, there is absolutely no reason why it must do so. Applied to the familiar question of the determination of long-term interest rates given short-term rates, for example, the structural model need do no more than replace the traditional single term-structure equation with one aggregate demand equation and one aggregate supply equation for long-term securities (plus the market clearing condition). At the aggregate level, therefore, the cost at which the modeler or forecaster need buy the advantages of the structural approach is just the replacement of one estimated equation by two.

The results presented below demonstrate that the structural modeling approach to interest rate determination not only stands apart from the sectoral disaggregation question conceptually but also performs fairly well without sectoral disaggregation empirically. This paper presents estimation and dynamic simulation results for an aggregated equivalent to the disaggregated model of the determination of bond yields developed in Friedman $(1977 ; 1979)$. Instead of six bond demand and two bond supply equations, here there are but one demand and one supply equation. The empirical results show that, while disaggregation

\footnotetext{
${ }^{3}$ Mayer (1976) listed a belief in the irrelevance of sectoral detail for aggregative outcomes as one of the four most central tenets of monetarist economics, but his list is not universally accepted.
} 
is of value in structural interest rate modeling (that is, the disaggregated model outperforms the aggregated one), even the aggregated structural model performs very well in comparison with familiar unrestricted reduced-form term structure equations.

\section{The Demand and Supply Equations ${ }^{4}$}

The model used in Friedman (1977) to represent investors' asset demands combined the linear homogeneous specification of desired portfolio allocation,

$$
\begin{aligned}
\alpha^{*}{ }_{i t} \equiv W_{t}^{-1} \cdot A^{*}{ }_{i t} & =\sum_{k}^{N} \beta_{i k} r_{k t}+\sum_{h}^{M} \gamma_{i h} x_{h t}+\pi_{i}, \\
i & =1, \ldots, N
\end{aligned}
$$

with the optimal marginal adjustment model of portfolio adjustment in the presence of transactions costs,

$$
\begin{aligned}
\Delta A_{i t} & =\sum_{k}^{N} \theta_{i k}\left(\alpha_{k t}^{*} \cdot W_{t-1}-A_{k, t-1}\right)+\alpha^{*}{ }_{i t} \Delta W_{t}, \\
i & =1, \ldots, N
\end{aligned}
$$

where

$$
\begin{aligned}
A^{*}{ }_{i t}= & \text { the investor's desired holding of the } i^{t \text { th }} \text { asset } \\
& \text { at time period } t\left(\Sigma_{i} A^{*}{ }_{i t}=W_{t}\right) \\
A_{i t}= & \text { the investor's actual holding of the } i^{\text {th }} \text { asset at } \\
& \text { time period } t\left(\Sigma_{t} A_{i t}=W_{t}\right) \\
W_{t}= & \text { the investor's total portfolio size (wealth) at } \\
& \text { time period } t \\
r_{k t}= & \text { the expected holding-period yield on the } k^{\text {th }} \\
& \text { asset at time period } t \\
x_{h t}= & \text { the value of any additional (risk related) } \\
& \text { variable influencing the desired allocation at } \\
& \text { time period } t
\end{aligned}
$$

and the $\beta_{i k}, \gamma_{i h}, \pi_{i}$ and $\theta_{i k}$ are fixed coefficients satisfying $\Sigma_{i} \beta_{i k}=0$ for all $k, \Sigma_{i} \gamma_{i h}=0$ for all $h, \Sigma_{i} \pi_{i}=1, \Sigma_{i} \theta_{i k}$ $=\dot{\theta}$ for all $k$ with $\bar{\theta}$ arbitrary, and $0 \leq \theta_{i k} \leq 1$ for $i=k$. Under the hypothesis of universal substitutability the $\beta_{i k}$ also satisfy $\beta_{i k}>0$ for $i=k$, and $\beta_{i k}<0$ for $i \neq k$. The bond demand equation consists of one of the $N$ components of the asset demand system found by substituting (1) into (2). ${ }^{5}$ Since the balance-sheet constraints noted above render only $N-1$ of these component equations independent, in a simplified model

4 Friedman $(1977 ; 1979)$ discussed in some detail the specifications used, and there is no point in repeating that discussion; hence the presentation in section I gives only the bare essentials. See the two earlier papers for substantive explanations.

5 Although the resulting expression has no constant term, it is probably accurate to consider both (1) and (2) as linear approximations to more complex behavior patterns, and a constant term may follow from linearization. The procedure used for estimation includes or excludes an intercept according to the standard error ratio. with only bonds and short-term assets this one equation would completely describe the investor's full system of asset demands.

The model used in Friedman (1979) to represent borrowers' liability supplies analogously combines (1) and (2) with

$$
\begin{aligned}
L^{*}{ }_{i t}= & \text { the borrower's desired amount of the } i^{\text {th }} \text { lia- } \\
& \text { bility outstanding at time period } t\left(\Sigma_{i} L^{*}{ }_{i t}=\right. \\
& \left.D_{t}\right) \\
L_{i t}= & \text { the borrower's actual amount of the } t^{\text {th }} \text { liabil- } \\
& \text { ity outstanding at time period } t\left(\Sigma_{i} L_{t t}=D_{t}\right) \\
D_{t}= & \text { the borrower's total cumulated external def- } \\
& \text { icit at time period } t
\end{aligned}
$$

replacing $A^{*}{ }_{i t}, A_{i t}$ and $W_{t}$, respectively. The conditions noted above continue to hold except that here $\beta_{i k}<0$ for $i=k$, and $\beta_{i k}>0$ for $i \neq k$.

\section{Estimation Results}

Friedman (1977) presented the results of estimating the model specified above for the separate demands for corporate bonds by life insurance companies, other insurance companies, private pension funds, state and local government retirement funds, mutual savings banks, and households, for quarterly U.S. data spanning the 1960:I-1973:IV sample. (As of year-end 1978 these six categories of investors together held $94 \%$ of all outstanding corporate bonds issued in the United States.) Estimating the analogous relationship for the aggregate of these demands, using Fair's (1970) twostage least-squares method ${ }^{7}$ and (for comparability of results) the same sample period, yields

$$
\begin{aligned}
& \Delta B_{t}{ }^{D}=5924+0.001086 W_{t-1}+0.07145\left(r_{B t} \cdot \Delta W_{t}\right)^{*} \\
& \text { (4.1) (2.3) (6.7) } \\
& \underset{(-4.3)}{-0.01294} r_{S t}^{e}: \Delta W_{t} \underset{(-6.0)}{-0.07556} r_{M t} \cdot \Delta W_{t} \\
& +0.0004336 r_{M t} \cdot W_{t-1}+0.0006528 r_{E t} \cdot W_{t-1} \\
& \text { (6.8) } \\
& -0.04689 B_{t-1}{ }^{D}-0.06532 U_{t-1} \\
& (-5.0) \quad(-4.1) \\
& \bar{R}^{2}=.99 ; \quad \mathrm{SE}=385 ; \quad \text { D.W. }=2.15
\end{aligned}
$$

6 Once again, there is no point in repeating discussions presented before. See the two earlier papers for descriptions of data and estimation methods, and for an evaluation of the empirical results.

7 In Friedman $(1977 ; 1979)$ it was impossible to use the direct two-stage least-squares procedure because, with the disaggregation, there were too many predetermined variables to permit ordinary least-squares estimation of the system's reduced form. With aggregation, the application of two-stage least squares is straightforward, although the evidence of serially corr elated residuals in an equation including a lagged dependent variable necessitates using a variant like Fair's. The estimated serial correlation coefficients are $\rho_{1}=-1.0106$ and $\rho_{2}=-0.4608$ in the demand equation, and $\rho_{1}=-0.5361$ and $\rho_{2}=-0.4117$ in the supply equation. 
where $\bar{R}^{2}$ is the coefficient of determination adjusted for degrees of freedom, $S E$ is the standard error of estimate (in millions of dollars), D.W. is the DurbinWatson statistic, the number in parentheses beneath each coefficient is the ratio of the estimate to its standard error, an asterisk superscript indicates a term for which the equation is estimated using first-stage fitted values, and the definitions of the variables not already defined above are

$$
\begin{aligned}
r_{B t}= & \text { yield on corporate bonds (Moody's Aa new- } \\
& \text { issue long-term utilities } \left.{ }^{8}\right) \\
r_{S t}{ }^{e}= & \text { average of current and expected future values } \\
& \text { of the short-term yield (prime 4-6 month } \\
& \text { commercial paper) } \\
r_{M t}= & \text { yield on municipal bonds (Moody's Aaa) } \\
r_{E t}= & \text { yield on equities (Standard and Poor's } \\
& \text { dividend/price ratio) } \\
U_{t}= & \text { holdings of U.S. Government securities. }
\end{aligned}
$$

The polynomial distributed lag proxy for $r_{S i} e^{e}$, generated within the estimation of (3), is 9

$$
\begin{array}{lll}
r_{S t}{ }^{e}=r_{S t}+\sum_{\tau=0}^{22} \delta_{\tau} \Delta r_{S, t-\tau} & \left(\sum_{\tau=0}^{22} \delta_{\tau}=1\right) \\
\delta_{0}=0.5312 & \delta_{8}=-0.1116 & \delta_{16}=0.2924 \\
\delta_{1}=-0.3444 & \delta_{9}=-0.0505 & \delta_{17}=0.3055 \\
\delta_{2}=-0.3460 & \delta_{10}=0.0115 & \delta_{18}=0.3036 \\
\delta_{3}=-0.3325 & \delta_{11}=0.0725 & \delta_{19}=0.2847 \\
\delta_{4}=-0.3062 & \delta_{12}=0.1304 & \delta_{20}=0.2469 \\
\delta_{5}=-0.2690 & \delta_{13}=0.1834 & \delta_{21}=0.1882 \\
\delta_{6}=-0.2228 & \delta_{14}=0.2294 & \delta_{22}=0.1066 \\
\delta_{7}=-0.1697 & \delta_{15}=0.2664 &
\end{array}
$$

Friedman (1979) presented the results of estimating the corresponding model for the separate supplies of corporate bonds by domestic nonfinancial business

8 The Moody's bond yield series is a size-weighted average of the yields on bonds actually issued (in contrast to judgmentally constructed yield series like, for example, Salomon Brothers').

9 The unit sum constraint is imposed to identify the coefficient on $r_{s t} e^{e}$. The distributed lag weights are constrained to follow a third-degree polynomial pattern, with the righthand tail of the lag constrained to pass through zero and with the lead lag weight free of the polynomial constraint (but still included in the unit sum constraint). In the joint estimation of (3) and (4), the standard error ratios are 3.4 for $\delta_{0}$, and 3.8 and -4.8 for the two polynomial variables. It is worth pointing out explicitly that a general autoregressive expectations proxy, while more general than the familiar adaptive expectation, is consistent with fully rational expectations formation only under the condition that the past history of the time series in question contains all of the available information which is relevant for predicting its future values. See Friedman (1980) and Friedman and Roley (1979) for attempts (largely unsuccessful) to represent more general expectations mechanisms at the disaggregated level. corporations and finance companies, for the same sample period. (As of year-end 1978 these two categories of bond issuers accounted for $88 \%$ of all outstanding corporate bonds issued in the United States.) Estimating the analogous relationship for the aggregate of these supplies, using Fair's method and the same sample, yields ${ }^{10}$

$$
\begin{aligned}
& \Delta B_{i}{ }^{S}=7253-2.115\left(r_{B t} \cdot \Delta D_{t}\right)^{*} \\
& \text { (6.1) }(-8.4) \\
& +1.810\left(r_{B t}^{e} \cdot \Delta D_{t}\right)^{*}+0.1436 r_{S t}{ }^{e} \cdot \Delta D_{t} \\
& \text { (8.5) } \\
& +0.01008 r_{S i}^{e} \cdot D_{t-1}+0.6521 x_{1 i} \cdot \Delta D_{t} \\
& \text { (7.3) } \\
& -0.1411 B_{t-1} s \\
& \text { (-5.9) } \\
& \bar{R}^{2}=.99 \quad \mathrm{SE}=332 \quad \text { D.W. }=2.12
\end{aligned}
$$

where the notation is as above and

$$
\begin{aligned}
r_{B t}^{e}= & \text { expected average future value of } r_{B} \\
x_{1 t}= & \text { ratio of the stock of fixed investment assets to } \\
& D_{t} .
\end{aligned}
$$

The polynomial distributed lag proxies for $r_{B t}{ }^{e}$ and $r_{S t}{ }^{e}$, generated within the estimation of (5), are, respectively, ${ }^{11}$

$$
\begin{aligned}
& r_{B t}{ }^{e}=r_{B t}+\sum_{\tau=0}^{8} \xi_{\tau} \Delta r_{B, t-\tau} \quad\left(\sum_{\tau=0}^{8} \xi_{\tau}=1\right) \\
& \xi_{0}=0.1384 \quad \xi_{5}=0.1090 \\
& \xi_{1}=0.1548 \quad \xi_{6}=0.0860 \\
& \xi_{2}=0.1514 \quad \xi_{7}=0.0597 \\
& \xi_{3}=0.1424 \quad \xi_{8}=0.0308 \\
& \xi_{4}=0.1280 \\
& r_{S t} e^{2}=\sum_{\tau=1}^{19} \phi_{t} r_{S, t-\tau} \\
& \left(\sum_{\tau=1}^{19} \phi_{\tau}=1\right) \\
& \phi_{1}=-0.06875 \\
& \phi_{2}=0.0612 \\
& \phi_{3}=0.0204 \\
& \begin{array}{ll}
\phi_{4}=-0.0052 & \phi_{7}=-0.0110 \\
\phi_{5}=-0.0176 & \phi_{8}=0.0040 \\
\phi_{8}=-0.0188 & \phi_{9}=0.0241
\end{array}
\end{aligned}
$$

10 Equation (5) also includes a dummy variable, with unit value in 1970:11 and zero value elsewhere, to allow for the effect of bond issuers' (positive) responses to the Penn Central bankruptcy.

1 The constraints on the distributed lag estimation are again as described in footnote 9 . In (6) the standard error ratios are 9.8 for $\xi_{0}$, and -1.3 and 0.6 for the two polynomial variables; the $F$-statistic for the effect of the two polynomial variables together is 4.72 (significant at the 0.05 level). In (7) the standard error ratios are -2.5 for $\phi_{1}$, and -1.7 and -0.0 for the two polynomial variables; the $F$-statistic for the effect of the two polynomial variables together is 11.61 (significant at the 0.01 level). The current value $r_{s t}$ was omitted from (7) after the results of estimating the equation with lag span $\tau=$ $0, \ldots, 18$ and $\phi_{0}$ free of the polynomial constraint indicated that it was impossible to reject the hypothesis $\phi=0$ at any reasonable level of significance. 


$$
\begin{array}{llll}
\phi_{10}=0.0472 & \phi_{13}=0.1145 & \phi_{16}=0.1364 \\
\phi_{11}=0.0713 & \phi_{14}=0.1296 & \phi_{17}=0.1240 \\
\phi_{12}=0.0945 & \phi_{15}=0.1375 & \phi_{18}=0.0986 \\
& & & \phi_{19}=0.0579
\end{array}
$$

The estimation results shown in (3)-(7) reproduce the essential features of the results found in Friedman $(1977 ; 1979)$ for the disaggregated equations. ${ }^{12}$ The aggregate demand for corporate bonds (3) depends positively on the current corporate bond yield and negatively on the expected average short-term yield and the municipal bond yield. ${ }^{13}$ The aggregate supply of corporate bonds (5) depends negatively on the current bond yield, positively on the expected average bond yield and the expected average short-term yield, and positively on the fixed asset ratio. In both the demand and the supply equations, the estimated ownstock adjustment coefficient is positive as expected, although in the demand equation the effect of the aggregation is to produce a slow estimated speed of adjustment in comparison to that in the disaggregated equations. Especially for the supply equation, the effect of the aggregation is to render insignificant several variables (for example, a retained earnings variable and the amount of equity retirements) that were significant in the disaggregated equations.

\section{Simulation Results and Some Comparisons}

Figure 1 plots the actual quarterly values of the Aa new-issue utility bond yield for 1960:I-1973:IV against the values generated by a dynamic simulation of the structural model consisting of the aggregate demand equation (3), the aggregate supply equation (5), and the market clearing condition ${ }^{14}$

$$
\Delta B_{i}{ }^{D}=\Delta B_{i}^{S}
$$

This simulation is fully dynamic in that, after 1960:I, it uses internally generated values for the lagged own stock variable $B_{t-1}{ }^{D}$ or $B_{t-1} s$ in both (3) and (5), as well

\footnotetext{
12 These equations are also comparable to those in Friedman $(1977 ; 1979)$ in that they omit any effect of expectations of price inflation. Friedman (1978; 1980) found significant effects of inflation expectations' on both bond demand and bond supply at the disaggregated le vel. Attempts to find such effects on aggregate bond demand and supply were unsuccessful; this negative result is consistent with the heterogeneity among the different sectors' respective inflation expectations representations found in Friedman $(1978 ; 1980)$.

${ }^{13}$ The structure of the model is inadequate to identify an a priori sign expectation for terms like $r_{M t} \cdot W_{t-1}$ and $r_{E t} \cdot W_{t-1}$ in (3), or $r_{s t}{ }^{e} \cdot D_{t-1}$ in (5); see again the discussion in Friedman (1977).

14 In addition, (8) nets out the small amounts of bonds either bought or sold by the categories of market participants excluded from the aggregate measures.
}

as internally generated values of $r_{B, t-7}, \tau>0$, for the lagged own-yield variable which enters (5) via (6). The dynamic simulation tracks the historical path of the bond yield with negligible mean error (less than 0.01\%) and with a root-mean-square error of $0.25 \%$. For the aggregate bond quantity variable the mean and rootmean-square errors are $\$ 19$ million and $\$ 420$ million, respectively.

As the first part of table 1 shows, this $0.25 \%$ rootmean-square error for the long-term interest rate in the aggregated model is inferior-but only modestly so-to the $0.21 \%$ root-mean-square error generated in an analogous dynamic simulation of the disaggregated model consisting of the six demand equations from Friedman (1977) and the two supply equations from Friedman (1979) (plus the same market clearing condition). For purposes of structural modeling of the determination of the long-term interest rate, therefore, the evidence is that disaggregation does indeed help-but not nearly so much as is popularly believed.

It is especially useful to contrast the dynamic simulation results for either the aggregated or the disaggregated structural model with the within-sample "fit" for familiar single-equation unrestricted reduced-form models. The equations estimated by Feldstein and Eckstein (1970, equation (10)), by Modigliani and Shiller (1973, equation (E-4)), and by Feldstein and Chamberlain (1973, equation (3.4)) had estimated standard errors of $0.09 \%, 0.13 \%$, and $0.24 \%$, respectively. In each case, however, these researchers not only used the Aaa yield, which is less volatile than the Aa yield used here, but also used sample periods which exhibited less interest rate volatility overall. ${ }^{15}$ Re-estimating the three respective unrestricted reduced-form equations using the Aa yield and the 1960:I-1973:IV sample period leads to the results shown in the lower part of table 1. Not surprisingly, the "fit" of each of the three equations deteriorates. For a given long-term interest rate and sample period, the structural model either aggregated or disaggregated clearly outperforms both the Feldstein-Eckstein model and the Feldstein-Chamberlain model. Only the Modigliani-Shiller model outperforms the structural model; and even it beats the disaggregated model by but a single basis point and the aggregated model by only five.

\section{Conclusion}

The popular presumption that structural models of interest rate determination must necessarily incorporate disaggregated sectoral detail is incorrect, both conceptually and empirically. From a theoretical

${ }^{15}$ The particular sample periods used were 1954:I-1969:11 by Feldstein and Eckstein, 1955:III-1971:II by Modigliani and Shiller, and 1954:I-1971:I by Feldstein and Chamberlain. 
Figure 1.-Dynamic Simulation Results for Aa UTILITY NeW ISSUE YiELD

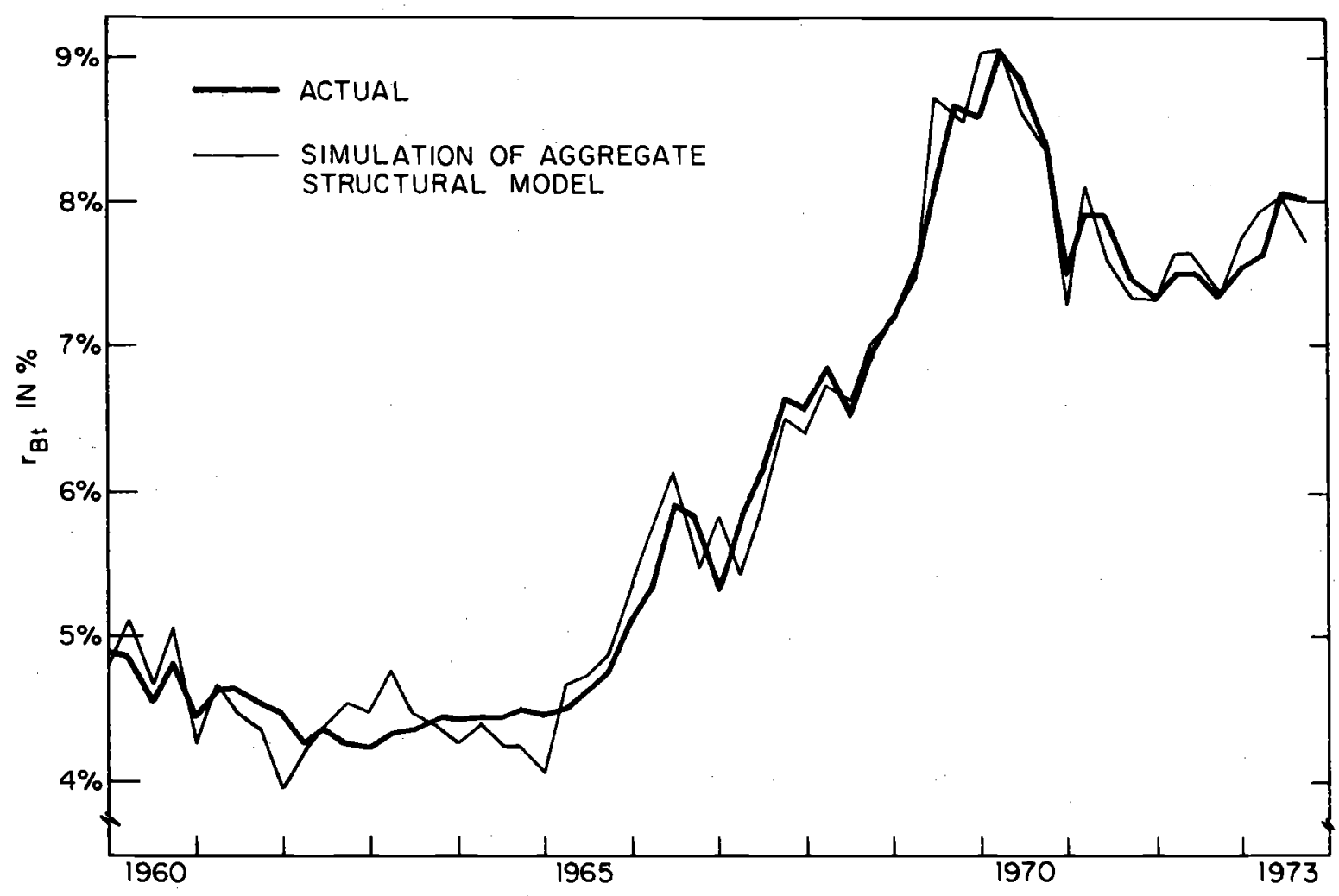

standpoint, constraining interest rate models via choice-theoretic statements of the underlying asset demand and supply behavior is just as relevant at the aggregate level as with disaggregation. Furthermore, the empirical results presented in this paper show that even an aggregated model of long-term interest rate determination performs comparably to widely recognized single-equation unrestricted reduced-form models. Comparison with an analogous disaggregated

Table 1.-Within-Sample Performance of AlternaTIVE LONG-TERM INTEREST RATE Módels

\begin{tabular}{lc}
\hline \hline Structural Models & Root-Mean-Square Error \\
\cline { 2 - 2 } Aggregated & $0.25 \%$ \\
Disaggregated & $0.21 \%$ \\
Unrestricted & \\
\hline Reduced-Form Models & Estimated Standard Error \\
\cline { 2 - 2 } Feldstein-Eckstein & $0.30 \%$ \\
Modigliani-Shiller & $0.20 \%$ \\
Feldstein-Chamberlain & $0.42 \%$ \\
\hline
\end{tabular}

Note: The three unrestricted reduced-form models were re-estimated for consistency with the 1960:I-1973:IV sample period and the Aa new-issue long-term utility bond yield. structural model shows that the disaggregation does help-but not nearly so much as is popularly believed.

Hence an aversion to dealing with disaggregated sectoral detail, either in model building or in forecasting applications, is not a valid objection to the structural approach to modeling interest rates. The determinants of interest rates in the simple aggregate model presented here-aggregate saving, aggregate business external funds requirements, and aggregate business fixed investment-are variables that model builders typically have already put in their models and forecasters into their forecasts. Additional sectoral detail is helpful, to some extent, but by no means necessary.

The attractiveness or otherwise of the structural approach rests instead on the distinction between restricted and unrestricted estimation. The two corollary advantages of the structural approach are its ability to use the theory of portfolio behavior to constrain the implied interest rate equation, and the facility that it provides for directly investigating hypotheses about portfolio behavior. This approach also largely avoids the problem of spurious correlations inherent in unrestricted estimation of the flexible distributed lags on 
past interest rates that are typically the core of interest rate models based on the expectations theory of the term structure. ${ }^{16}$ In return, the structural approach imposes on the researcher the discipline of explicitly acknowledging that, since interest rates are proximately determined in a market in which financial assets are bought and sold, any factor hypothesized to influence interest rates can do so only by influencing some investor's asset demand or some borrower's corresponding supply. Whether the advantages are worth the added discipline may be an open question, but the answer does not much depend on issues of disaggregation.

16 In a structural model any such distributed lags simply appear as arguments of the asset demand and supply equations, where spurious correlation is both less likely and less harmful. This issue arises in models based not only on autoregressive expectations proxies but also on rational expectations proxies, since consistent estimation of the latter requires an instrumental variables procedure, and lagged interest rates are plausible (partial) instruments for this purpose.

\section{REFERENCES}

Bosworth, Barry, and James S. Duesenberry, "A Flow of Funds Model and Its Implications," Issues in Federal Debt Management (Boston: Federal Reserve Bank of Boston, 1973).

Dick, Stacy S., A Structural Model of the Market for Municipal Bonds, A.B. honors thesis, Harvard University, 1978.

Fair, Ray C., "The Estimation of Simultaneous Equations Models with Lagged Endogenous Variables and First Order Serially Correlated Errors," Econometrica 38 (May 1970), 507-516.

Feldstein, Martin, and Gary Chamberlain, "Multimarket Ex- pectations and the Rate of Interest," Journal of Money, Credit and Banking 5 (Nov. 1973), 873-902.

Feldstein, Martin, and Otto Eckstein, "The Fundamental Determinants of the Interest Rate," this REVIEW 52 (Nov. 1970), 363-375.

Friedman, Benjamin M., "Financial Flow Variables and the Short-Run Determination of Long-Term Interest Rates," Journal of Political Economy 85 (Aug. 1977), 661-689.

-, "Who Puts the Inflation Premium into Nominal Interest Rates?" Journal of Finance 33 (June 1978), 833-845.

- "Substitution and Expectation Effects on Long-Term Borrowing Behavior and Long-Term Interest Rates,' Journal of Money, Credit and Banking 11 (May 1979), $131-150$.

_ " Price Inffation, Portfolio Choice and Nominal Interest Rates," American Economic Review 70 (March 1980), 32-48.

Friedman, Benjamin M., and V. Vance Roley, "Investors' Portfolio Behavior Under Alternative Models of Long-Term Interest Rate Expectations: Unitary, Rational, or Autoregressive," Econometrica 47 (Nov. 1979), 1475-1497.

, "Structural Versus Reduced-Form Models of LongTerm Interest Rate Determination," Journal of Portfolio Management, forthcoming.

Hendershott, Patric H., Understanding Capital Markets, Volume I: A Flow-of-Funds Financial Model (Lexington: D.C. Heath \& Co., 1977).

Mayer, Thomas, "The Structure of Monetarism," Kredit und Kapital 8 (nos. 2 and 3) (1976), 190-218, 293316.

Modigliani, Franco, and Robert J. Shiller, "Inflation, Rational Expectations, and the Term Structure of Interest Rates," Economica 40 (Feb. 1973), 12-43.

Roley, V. Vance, A Structural Model of the U.S. Government Securities Market, Ph.D. dissertation, Harvard University, 1977.

Silber, William L., Portfolio Behavior and Financial Institutions (New York: Holt, Rinehart and Winston, Inc. 1970). 